\title{
THE RELATIONSHIP BETWEEN IDENTITY, LANGUAGE AND TEACHING AND LEARNING IN HIGHER EDUCATION IN SOUTH AFRICA
}

\author{
Brenda Leibowitz \\ Hanelie Adendorff \\ Shariefa Daniels \\ Ansie Loots \\ Sipho Nakasa \\ Nosipiwo Ngxabazi \\ Antoinette Van der Merwe \\ Idilette Van Deventer \\ University of Stellenbosch
}

The study on the relationship of identity, language and teaching and learning was conducted by a team of eight members at a higher education institution in the Western Cape. The aims of the research were to investigate the relationship between language, identity and learning, to show how this investigation can benefit dialogue about transformation, and to facilitate the research development of the team. The research design made use of narrative and educational biography in semi-structured interviews with 64 staff members and 100 students. The study supports views of identity as constructed and non-unitary. It shows how language, both as proficiency in the dominant medium of communication and as discourse, is a key component of identity in a higher education institution. The interviews demonstrated how, according to lecturers and students, language and discourse function as primary influences on individuals' acculturation and integration into the academic community. According to the interviewees, language as a marker of identity is interwoven with other aspects of identity. It is both a resource and a source of identification and affiliation. The research demonstrated that dialogue and self reflection can be facilitated via research into identity, teaching and learning, and that this can be beneficial for both the interviewees and the research team.

\section{INTRODUCTION}

\section{The higher education setting}

For some years now higher education internationally has been finding ways of meeting the challenge to become more inclusive (Drakich, Taylor \& Bankier, 1995). In South Africa, the challenge to become more inclusive is reflected in many post-apartheid policy documents on education. The concept of inclusion in particular embraces values such as democracy, openness and a human rights approach to education (Department of Education, 2001). Inclusive education values difference and aims to eliminate overt or covert discrimination. The South African Education White Paper 3 (1997) calls for 'ensuring that the composition 
of the student body progressively reflects the demographic realities of the broader society', amongst African, Coloured and women students in particular (2.24) and equally importantly, that increased access must be accompanied by efforts to achieve 'equity of outcomes' (2.29).

Despite these policy imperatives regarding transformation in higher education in South Africa, there is still a disjuncture between the policies and practices (Carriem, 2003). The challenge to diversify the staff body and ethos in higher education, for instance, has not yet been met. The current lack of an inclusive culture is reflected in Mabokela (2000: 111), who states that at the Universities of Cape Town and Stellenbosch, 'Black academics expressed feelings of alienation and institutional culture that some perceived as hostile'. This exclusive culture affects students as well as staff. In a study conducted with students at the Western Cape, Leibowitz (2001) found that African students in the predominantly coloured university repeatedly referred to themselves as 'African', in the minority and as being expected to adapt socially and academically to the mainstream. Walker (in press) surveyed the life history narratives of 12 black and white undergraduate students at a historically white Afrikaans medium university. She concludes that 'all of these students' lives are marked, whether acknowledged or not, by race, by racialised subjectivities, and by a past of racial separateness'.

The challenge to generate an inclusive university culture has been paralleled by a failure to generate equity of educational outcomes amongst higher education students. In response to data on student composition and throughput rates, Cloete and Bunting (2000: 32) conclude that 'the university sector had not by 1998 met the White paper's performance goal of improving the success rates of black students'.

The question which one may ask is: 'how can education researchers in higher education contribute towards the process of transforming the ethos and learning culture in South African universities?' One way of doing this is to generate dialogue and self-reflection on issues of role and identity amongst staff and students. This article suggests that such dialogue and self reflection can be generated via research on staff and students' language and educational biographies.

\section{Aims of the Identity, Teaching and Learning Research Project}

The research team comprising eight individuals working in academic support centres at a Western Cape university jointly investigated the relationship between identity, teaching and learning at the university in 2004. The team members were drawn from a variety of disciplinary backgrounds, including natural science, education, psychology and language. The research aims were:

$>$ To investigate the relationship between identity, teaching and learning;

$>$ To use this understanding in order to make suggestions for ways to improve conditions for teaching and learning at the site of study;

$>$ To investigate the use of various research methodologies, in particular, educational biographies, as a tool to further dialogue about identity, teaching and learning;

$>$ To undergo capacity building as a team in relation to social science research methods. 
An important thread in the research was the issue of identity and learning and teaching, is that of language. Several members of the team chose to focus on this in more detail. This thread forms the basis of this article.

\section{IDENTITY, LANGUAGE, AND TEACHING AND LEARNING}

\section{Identity}

The working definitions of 'identity' on which the research is based include the constructivist and post structural ideas that identity is not real, inherent or unitary, but rather, that it is fragmentary, constructed through meaning making and representation (Hall, 1992). It is signaled and understood through the process of telling stories about who we are, thus via narrative, (Sfard and Prusak, 2005). Identity markers and labels offer individuals a way of defining themselves in relation to the world:

Social, discursive, and narrative options offered by a particular society in a specific time and place to which individuals and groups of individuals appeal in an attempt to self-name, to self-characterise, and to claim social spaces and social prerogatives (Pavlenko and Blackledge, 2004:19).

Castells (1997: 10), with reference to Giddens, argues for the value of knowing and understanding oneself, which he refers to as 'self-identity'. Identity varies according to context. Overt references to identity tends to be more common amongst individuals or groups perceiving themselves to be in the minority (Norton, 2000). In academia those in positions of power or in the dominant group do not always name their identities and tend to view their affiliations, heritage, values and norms as neutral or universal (...). Identity comprises an individual or group's conceptions of the past and the present, as well as their aspirations for the future. According to Wenger (1998:155) 'as trajectories our identities incorporate the past and the future in the very process of negotiating the present'.

Identities comprise elements which might be given, such as one's social class, or physiologically inherited characteristics, as well as elements of choice or agency (Thesen, 1997; McKenna, 2004). Lopez (cited in McLaren, 1997: 271) describes identity as a combination of 'chance', 'context' and 'choice'.

\section{Language and identity}

According to Pavlenko and Blackledge (2004: 3) the relationship between language and identity has, until recently, been undertheorized. Traditionally identity is associated with a speaker's home language. Attitudes towards particular languages and speakers of those languages are influenced by the status and power associated with those languages. Mother tongue or first language as marker of identity might be particularly strong when one's own language is marginalized, for example, as a speaker of an African language at a predominantly English university. It has also been argued that spoken or home language as marker of identity or source of affiliation is a feature of some social groupings more than others ${ }^{1}$.

A second element linking language with identity is that of discourse. Discourse, as defined by Gee (1990) is an overarching cluster of features including that of mother tongue or 
proficiency in an additional language. Discourse is the ways of using words in association with the values and norms of that particular way of thinking about the world and of interacting with knowledge. In this sense language broadly understood (not just proficiency in a first or additional language) is a key component of identity. It plays a role in structuring the way we view society and culture (Bourdieu \& Passeron, 1994). According to Dillabough identity relations are shaped by social and structural relations and are situated in language. Through language they are 'intersubjectively embedded' (2000: 339).

Discourse is less frequently mentioned as a marker of identity than home or additional language, since as a concept does not feature frequently in everyday or commonsense discussions. However, it is mentioned by students who are feeling particularly marginalized as non-users of the dominant academic discourse of the university (Leibowitz, 2004; Boughey, 2005). Despite its invisibility to lecturers and students, discourse remains one of the key feature of an individuals' identity, which influences academic success at university (Leibowitz, 2004; Boughey, 2005). Thus language broadly understood is an identity marker, a source of affiliation, as well as a resource in an individual's personal life history. It is an important component in the 'chance' and 'context' of an individual's identity, but it is also bound with the 'choices' individuals make, consciously or unconsciously (Norton Peirce, 1997, Thesen, 1997, McKenna, 2004).

\section{Identity, teaching and learning}

The influence of language in relation to teaching and learning as discussed above is that it marks lecturers and students from, or affiliates them with the dominant languages and discourses of the university. It affects the way lecturers and students relate to each other, or make assumptions about each other, based on the associations speakers make about the perceived language affiliation of the other. This is often done in combination with other markers of ethnicity, such as race. Dynamics within discourse affect the teaching and learning process in a variety of ways. They provide learners with the sense of motivation or sense of purpose in completing written tasks (Clark and Ivanič, 1997) or investment to acquire the dominant languages (Norton Peirce, 1997). Discourse also provides lecturers and students in a multilingual and socially diverse environment with varying levels of confidence in their ability to learn. A certain measure of confidence that learning will take place is needed for a learner to engage with the curriculum. Gee (2003) calls this the 'regime of competence' principle. Sense of a learner's capability to learn an additional language is an important aspect of their identity, according to Norton (2000), but she maintains that this is also reliant on the material and structural conditions in their context. Proficiency in the language of instruction combined with social class features is a significant factor impacting on students' success in learning a dominant language, and on students' success in learning in a dominant language. This point has been made most often in relation to school education around the world (Lankshear, 1997; Heller, 1996; Arthur, 1996; Lin, 1996; Ndayipfakamiye, 1996) but it is applicable to higher education in South Africa as well.

An important contribution to the explanation of the relationship between identity and learning and teaching is the work on communities of practice. The extent to which individuals have participated in certain communities of practice, and in certain practices, determines the extent to which they enjoy ownership of meaning and can negotiate that meaning. According to Wenger (1998: 155), identity trajectories 'provide a context in which to determine what, among all the things that are potentially significant, actually becomes significant learning'. 
Gee (2003) and Wenger (1998) note the lack of ownership of meaning and lack of control when the individual cannot take on the identity of the dominant community. Walker (in press) maintains that 'The University is an important location for the ensuing identity work as a site where discourses collide, are distorted or articulate'. An example of dislocation and the lack of ownership of meaning in the Southern African context is provided by Leibowitz (2001). In her study African students, especially from rural areas, reported that their prior knowledges and values were not understood or valued by many white and coloured lecturers, and that this impacted negatively on their learning and their engagement with written assignments.

\section{Social justice}

Engaging in reflection on the self or an institution, referred to as 'reflexivity' by Giddens (1991), is an important component within the drive for transformation. In institutions of higher education dominant norms are espoused and inculcated within the curriculum and disciplines without this being made overt. The consequence of the so-called 'hidden curriculum' is that marginalized lecturers as well as students have an invisible set of obstacles and hurdles to conquer, and that members of dominant language and discourse groups are frequently unaware of how they are excluding the 'other'. Sayed and Soudien (2003: 17) call for a closer 'conscious and self-conscious consideration of identity and role', of who is doing the including and excluding, and who is choosing to do so. Kwenda (2003: 71) uses the term 'cultural justice' to refer to the sharing of self-consciousness amongst those users of the dominant cultural forms and the users of subjugated languages or cultural practices. Fraser (2003) makes a distinction with regard to social justice between 'recognition' and 'distribution'. 'Recognition', which is the granting of respect and the right to participate to those who are oppressed in terms of identity categories such as gender, sexual orientation or race, and in the South African context, speakers of certain marginalized languages. 'Distribution' involves the redistribution of material and other resources, for example, in the higher education context, salaries, research funds, power, discourse and access to the knowledge and communicative practices. This research project is based on the assumption that institutions seeking to transform themselves into inclusive teaching and learning environments would undertake self-conscious explorations of identity and role. The purpose of this self reflection is not purely to engage in navel gazing, but to better understand how to bring about greater recognition and distribution of material and cultural or linguistic resources.

\section{RESEARCH DESIGN}

The research was conducted in the form of a case study of a university in the Western Cape. The most significant feature of this university is that the majority of lecturers and students are white and the majority language is Afrikaans. The majority language is also the language of power, as inscribed in university policy. This case study was viewed as the first stage in the research. The intention is to broaden the study to other universities in the region at a later stage. The intention is also to use the findings to design the framework of an action research collaboration with a group of lecturers at the university. The focus of that research will be on effective teaching in contexts of diversity. 
The research was intentionally exploratory and iterative (cf. Aspland, 2003) so that insights gleaned from the pilot and early interviews would lead to a reshaping of the research design, questions and approaches to data thereafter. This was especially important given the fact that the research process had a strong capacity building component for the whole team, including the team leader. The fact that the research team were particularly open to new insights and ways of conducting the research was in keeping with the ideas of research for social justice, which, according to Griffiths (1998: 128) is concerned with:

who has a say, whose viewpoints count and the socio-political dimensions of all this, and whether the researcher, and everyone else, is prepared to change their minds as a result of coming into contact with alternative perspectives.

In keeping with the exploratory and capacity building spirit, the team began the research with a pilot phase in which each member conducted an interview with one other team member and with an additional academic outside the team. A strong motivation for the pilot focusing on the team members was the need to foster self-reflexivity amongst lecturers, and by extension, amongst members of the research team. The self-research component was also an attempt to avoid the danger of voyeuristically analyzing the lives and feelings of others. Burbules (2000: 268) refers to this as a 'cannibal desire to know the other'.

The key data gathering method used in this study was the interview, either one on one audiotaped interviews with lecturers, conducted by the team, or small group interviews conducted by senior students with fellow students. The senior students were trained by the team, and were themselves interviewed during the training sessions in order that they could experience being interviewed.

All interviews were semi-structured, beginning with a request directed to the interviewee to narrate their educational biography. This was followed up by questions for clarification and prompts to fill in gaps according to key issues outlined in advance by the team. The use of narrative was seen as an important vehicle to elicit lecturers' and students' views, perceptions and experiences, given the close relationship between narrative and identity. According to Sfard and Prusak (2005), identity is the story which we as individuals tell about ourselves, about who we are, who we want to become, or about how others see us. This view is shared by Pavlenko and Blackledge, for whom identity is the 'narrative options' to which an individual appeals (2000: 19). Biographies or life histories are an appropriate way to capture how attitudes towards an aspect of education develop over time (Aspland, 2003). They facilitate the researchers' understanding of the individuals' interpretations of events, and individuals' motivations for their actions (Ward, 2003). Stroobants (2005: 49) claims that the narrative process encourages 'biographical reflexivity and biographical agency' on the part of the interviewees, as they may use the research process to reflect on their experiences and on what strategies to use in the future. Stroobants maintains that the narrative process forces strong engagement on the part of the researcher, who also learns from the process.

The data which were finally captured consisted of interviews with 64 lecturers and academic support staff members. The criteria for the selection of lecturers was that they would span categories of identity at the university, such as gender, race, language, discipline and seniority. The minority groups were given more prominence in order to provide space for their perspectives, which could have been missed if a statistically representative sample approach was used. Since the purpose of this research was to understand issues and 
relationships rather than to conduct a survey or to represent the institution as a whole, this lack of representativity of the university population as a whole was not seen as a problem. In addition to the interviews, 34 staff members and all students filled in a short questionnaire at the end of the interview. The addition of a questionnaire after the pilot phase was decided upon by the team in order to cover gaps in the interviews, and in order to provide interviewees with a chance to consolidate and reflect on the discussion.

Further data consisted of interviews with 100 students in small groups. The final selection was strongly influenced by a 'convenience sampling' approach, since the students struggled to elicit interest in being interviewed from students they did not know. Since the team of senior students was itself diverse in terms of gender, race, disciplinary background and seniority, the approach allowed a wide range of students to be interviewed.

Additional rich data were obtained from the audio-taped discussions on the research process by the research team and from audio-taped discussions during the training of the student team. All recordings were transcribed soon after the discussions had been completed and are in the process of being analysed according to key questions and themes generated by the research aims and questions, by the data and by the research literature on identity and teaching and learning. The main question informing the analysis in relation to language in identity is: 'How do lecturers and students describe the relationship between their academic identities and their home and academic languages in an institution undergoing transformation?' Flowing from this is the question, 'What can an investigation into the relationship between lecturers' and students' language and academic identities contribute to processes of transformation in higher education?'

\section{RESEARCH FINDINGS}

\section{Language and identity}

The interviews generally supported a post-structuralist account of language and identity as described in section 2, where identity varies according to context and is fractured. This point was highlighted in the team discussions after the pilot interviews, when one team member described how difficult it is to define one's identity:

I also had the feeling that apart from the fact that identities change, I feel that you also have different identities in different situations, I had a clearer idea of my identity as a student and even as a young academic, but now I'm a scientist, I'm an academic development worker, I am a humanitarian at times, I'm a parent at times, but who am I actually, obviously not four different people, so that I personally found very difficult to decide, what is my identity, it seemed to me clearer ten years ago.

How interviewees accounted for language as identity marker amongst other identity markers in their stories, was in itself worthy of investigation. A statistical account of how the lecturers described themselves showed language as a key marker: language was mentioned by $61 \%$ of the lecturers; academic discipline by $57 \%$; gender by $53 \%$; race by $51 \%$ and religion by $47 \%$. Furthermore language tended to be mentioned in combination with race, culture or gender, as well as nationhood, as in the following examples: 
Well, being an African and being a Xhosa in my understanding is one and the same thing.

I am a white Afrikaner middle-aged male (endangered species!)

Afrikaans speaking South African.

The linkage of language and culture also featured in lecturers' descriptions of others, as is evident in the following example:

In fact there's a student being inducted now on Afro-centric case-work. He's a Venda ${ }^{2}$. And that's one of the things where I think we still have a lot to do ... to be more sensitive to a lot of those cultural aspects. We know too little about it.

The interrelatedness of language with other identity markers as exemplified in the above quote has important implications for debates around transformation of teaching and learning: one cannot adopt change interventions based on isolated phenomena or factors, without considering how embedded these factors are in a myriad of interweaving elements, some more directly cognitive, and others, more directly ideological or affective.

The interweaving of the cognitive and the affective is evident in a comment by a staff member who spoke both IsiXhosa and English, but not Afrikaans. She spoke about coming to the university and attending an induction course in Afrikaans:

I am reminded about when we went for our induction, it was a traumatic experience actually, not being made to feel that you are part of [the university], not following most of what was said... it was probably the Afrikaans.

Although references to language do feature in interviewees' accounts of identification or marginalization in the institution, these are less prominent than references to race. The following extract from an interview with a staff member demonstrates how language is one amongst several of the conditions of 'otherness' referred to by a staff member. Her account is steeped in words denoting contrast and distance:

I identify myself as a black South African, woman, psychologist who is nonAfrikaans speaking in an Afrikaans institution. That's me. If you want more then I could say, I'm a Xhosa speaking, just turned 32, not married, from the Eastern Cape, who is also from a different province, far away from home.

This extract confirms the point made by Norton that people growing up in homogenous societies are less likely to define themselves as 'ethnic' (2002:12) whereas those in the minority to tend to do so. What was particularly striking in the accounts of otherness amongst lecturers who felt themselves to be in the minority in the institution, was that they stressed a determination to succeed. This was also evident in students' accounts. This does not demonstrate that minority individuals are determined to succeed, but rather, suggests that determination to succeed is one of the features that distinguishes those that remain, or who continue to participate, as opposed to those who leave, or who remain marginal. 


\section{Attitudes towards language in relation to teaching}

The issue of language of instruction was contentious at the time the interviews were conducted. It tended to feature as a topic of discussion in the interviews with speakers of Afrikaans more than amongst speakers of other languages. Amongst the speakers of Afrikaans five most common sentiments were: a love of Afrikaans but a concern that it was playing a politically driven or exclusive role; an irritation or lack of interest in the debate around language, 'I work in the trenches where we adapt according to battlefield conditions and view the utterances of language generals with amusement'; a desire to do what is most practical; and a belief that the use of Afrikaans is not exclusionary. Examples of different opinions are the following contrasting attitudes towards the identity and role of the university in relation to Afrikaans:

Afrikaans belangrik vir identiteit van Universiteit (Afrikaans important for identity of University).

I love the Afrikaans language and would hate to see it disappear. I have come to know the world through the medium of Afrikaans, and I believe that that experience bestows a texture on the meaning of the world that is unique and valuable. It is a great privilege to be able to enter the world of learning and knowledge in one's mother tongue. At the same time, I do not believe that it can ever be a basic function of a university to save a language. ... If people, however, don't want it any more, the university can't be the saviour.

This variation of sentiments mirrored the variation of sentiments amongst Afrikaans speaking lecturers on a variety of topics related to language, for example, attitudes towards transformation and the role of Afrikaans speaking people in post-apartheid South Africa. The evidence of diversity of opinion amongst the dominant group featured as one of the early lessons of the research: that amongst apparently homogenous groups there is much diversity. The implication is that one should be wary of making assumptions about individuals categorized by an identity marker such as home language.

\section{Language as resource}

Amongst students proficiency in the dominant language is a resource which facilitates or hampers one's ease of interaction with an institution. The following comment illustrates how a student who does not possess adequate proficiency in the language had to seek help from a variety of sources, before even arriving at the institution:

I remember that I had to fill in some forms that were written in Afrikaans, I had to use a dictionary and had to ask my Afrikaans teacher to help me.

Academic discourse was one of the most significant resources that influenced academics' careers. Academic discourse acquired in the home included an awareness of the importance of education and love of knowledge, access to literacy and in a phrase popularised by Heath (1983), 'ways with words'. One example of a communicative practice acquired in the home was of a strongly oral mode, according to an IsiXhosa speaking lecturer: 
The main thing was the transference of knowledge from the parents by word of mouth. Well, my mother was a housewife. She brought us up with stories. We had to listen to her for language and, you know, learnt a lot more about how to speak your language properly. Most of the information would be communicated orally.

The oral mode is less valued than the written mode at university. However since this speaker was a lecturer in African Languages, the oral mode is a valuable resource, as the value of the oral mode is central to the curriculum of the study of African languages.

Gee (1990: 2003) stresses the ease with which middle class individuals acquire academic discourse at school or university, because of the similarity of middle class communicative practices with academic discourse. This is demonstrated in a comment from a head of a department who learnt various debating and analytic skills at home, which she was able to put to good use in her present academic position:

Through the way in which we were brought up I did get a lot of academic debate, ... you have to articulate your argument clearly... If things are different then you have to show that they're different and not start muddling things ... and that part of being educated [is typical] in this department.

Thus language is a resource which advantages certain individuals in relation to academic success. It is also an identity marker which encourages a sense of affiliation or marginalization in relation to an institution. The notion of social justice encompassing the imperatives of recognition as well as redistribution, as discussed in 2.4 , is pertinent in relation to language. Transformation requires attention to the ways in which individuals' home and academic languages are valued and respected, as well as ways in which individuals' linguistic resources can become forms of cultural capital, and sources of power in the knowledge economy.

\section{REFLECTIONS ON THE RESEARCH PROCESS}

A small number of staff interviewees (11\%) indicated that they felt awkward talking about themselves, or that the interviews stirred up hurtful memories and emotions. Several staff members indicated that they felt affirmed and that they valued the opportunity to reflect on their own histories (24\%), which is in line with the claim made by Stroobants (2005) that engaging in narrative biographies encourages reflexivity on the part of participants. Half the students indicated feeling positive about the interview, with 30 indicating they found the interview interesting or that it caused them to reflect on their identities.

According to Stroobants (2005) participating in narrative biographical research requires strong engagement from the researchers. It is therefore not surprising that the most dramatic impact of the research process thus far has been on the team itself. One of the research team members put it this way:

Initially I saw the project as an opportunity to talk and thereby inform other people about diversity issues from a perspective that is different from theirs. In doing so I thought I could help create a bigger understanding and awareness of the 'other'. 
The most amazing thing is that the research thus far has been how it impacts on me as a person.

In addition to providing members of the team with an opportunity to practise doing qualitative social research with an education focus - some for the first time - the research process allowed the team to debate substantial issues regarding social justice in the context of unequal power relations. Team discussions on the findings revealed different approaches to issues of inclusion. One example is a discussion on an earlier draft of this article, in which a section heading, 'sharing the learning space', had been used. One team member found this patronizing, as it assumes that the dominant group has ownership of the learning space, and that it is their prerogative to share this. Another team member admitted that she had not thought of the university in this way. She saw herself as 'liberated', but this comment forced her to reconsider her opinion. The debates allowed the members to penetrate the issues of difference and identity more critically than they might otherwise have done:

We can say we agree or understand each other, but there are many levels of 'truth' and many of us are less inclusive that we acknowledge.

Senior student team members reported similar benefits from participating in the research. The following quote from one of the senior students, who was also a member of the Black Students Society, and therefore deeply engaged in matters of identity negotiation at the university, demonstrates the kind of lessons about identity matters that participating in the research could generate:

I've started looking at diversity with greater depth ... and the funny thing is, when you sit and look at people you just assume that they're alike, but even in homogeneous groups you'll find people come from completely different backgrounds and they view the world completely differently.

One constraint on the use of the senior students is that these students do not receive course credits for their participation. Several students were very enthusiastic about participating in the process, but found that they had underestimated the free time they had available. Payment for this source of work is low and is in many cases insufficient to sustain the engagement. This sense of overload was experienced by the research team as well. Despite the relevance of the research for their work, the volume and intensity of the research, and the fact that they were treated as service staff rather than academics, made it difficult to integrate this research process into their already busy professional lives.

The research process was affected by some of the same issues which it investigated, throwing these into sharp relief, and emphasizing the relationship between identity, language and power. A particular challenge thrown up by research conducted by a multilingual team in a multilingual environment where the balance of power legitimates the dominant languages, is the use of language in interviews. It became evident during the training of the student research assistants, that some interviewers could only conduct interviews in English, whereas others could do so in English and Afrikaans. At one of the training sessions it was said that the interviews would be more successful if interviewees were allowed to express themselves freely in the language of choice. However, an isiZulu speaking student indicated that she could not understand why the team should bend over backwards for speakers of Afrikaans, when she herself had not enjoyed the privilege of speaking freely in her home language at 
school or university. Furthermore, team members who do not read Afrikaans fluently will not have access to all interview transcripts. It was not even considered a possibility by the team that interviews could be conducted in isiZulu or isiXhosa, until after the pilot interviews were conducted.

\section{CONCLUSION}

The case study supports the notions of identity as constructed and as comprising a variety of markers which are chosen consciously or unconsciously by individuals. It also demonstrates the extent to which identities are imposed on individuals in contexts of difference and unequal power relations. The narratives demonstrate that language plays a role as resource and source of affiliation in the lives of lecturers and students. The relationship between identity and language intersect with teaching and learning in many spheres, including with an individual's sense of belonging and affiliation to an institution, and with an individual's integration into the academic community of practice. In this case study the role of language was stated overtly by many, but by no means all individuals, despite the fact that at the institution in which the investigation occurred, language is a strongly debated and emotive topic.

The study supports the argument that social justice involves both recognition and redistribution of power, and shows how language and discourse are interwoven into these considerations.

Finally, the study demonstrates the value of investigations into the relationship of language, identity and teaching in a university in post-apartheid South Africa. Such investigations allow for a more nuanced view of groups than might otherwise be the case. Lessons gleaned from this investigation provide pointers for dialogue about change at an institution and for researchers who help shape this dialogue.

\section{ENDNOTES}

${ }^{1}$ See Myhill (2004) on how for example the everyday spoken language has traditionally not been a marker of identity amongst Jews.

${ }^{2}$ In this case 'Venda' refers both to a speaker of the Venda language, and to a bearer of the Venda culture.

\section{ACKNOWLEDGEMENTS}

Dr Melanie Walker of Sheffield University played an important role in shaping the initial conceptualisation of the broader research project on identity, teaching and learning, of which this focus forms a part.

The NRF provided financial support towards the implementation of the identity, teaching and learning project. The anonymous reviewers substantially helped to shape the revision of this article.

\section{REFERENCES}

ARTHUR, J. 1996. Code switching and collusion: Classroom interaction in Botswana primary schools. Linguistics and Education, 8(1)17-33. 
ASPLAND, T. 2003. A research narrative: Confronting the tensions of methodological struggle. In O'Donoghue, T \& K Punch (eds), Qualitative research in education; Doing and reflecting. London: Routledge Falmer, 126-151.

BOURDIEU, P \& J PASSERON. 1994. Introduction in Bourdieu, P, J Passeron \& M de Saint Academic discourse. Cambridge: Polity Press.

BOUGHEY, C. 2005. 'Epistemological' access to the university: An alternative perspective. South African Journal of Higher Education, 19(3); 638-650.

CASTELLS, M. 1997. The power of identity. Oxford: Blackwell.

BURBULES, N. 2000. The limits of dialogue as a critical pedagogy. In Trifonas, P (ed.), Revolutionary pedagogies: Cultural politics, instituting education and the discourse of theory. NY: Routledge, 251-273.

CARRIEM, C. 2003. Race and inclusion in South African education, IDS Bulletin, 34(1): 2028.

CLARK, R \& R IVANIČ. 1997. The politics of writing. London and NY: Sage.

CLOETE, N \& I BUNTING. 2000. Higher education transformation: Assessing performance in South Africa. Pretoria: Centre for Higher Education Transformation (CHET).

DEPARTMENT OF EDUCATION. 2001. Manifesto on values, education and democracy. Pretoria.

DILLABOUGH, J. 2000. Degrees of freedom and deliberations of "self"; the gendering of identities in teaching. In Trifonas, P (ed.), Revolutionary pedagogies: Cultural policies, institutional education, and the discourse of theory. NY: Routledge.

DRAKICH, J, M TAYLOR \& J BANKIER. 1995. Academic freedom is the inclusive university. In Richer, S \& L Weir (eds), Beyond political correctness: Towards the inclusive university. Toronto: Toronto University Press, 118-135.

FRASER, N. Social justice in the age of identity politics: Redistribution, recognition, and participation. In N Fraser \& A Honneth (eds), Redistribution or recognition? A political-philosophical exchange. London: Verso, 57-67.

GEE, J. 2003. What video games have to do with literacy and learning. New York: Palgrave MacMillan.

GEE, J. 1990. Social linguistics and literacies: Ideology and discourses. London: Falmer.

GIDDENS A. 1991. Modernity and self-identity: Self and society in the late modern age. Cambridge: Policy Press.

GRIFFITHS, M. 1998. Education research for social justice: Getting off the fence. Buckingham and Philadelphia: Open University Press 
HALL, S. 1992. The question of cultural identity. In Hall, S, D Held \& T McGrew (eds), Modernity and its futures. Cambridge: Open University Press, 273-326.

HEATH, SB. 1983. Ways with words; language, life and work in communities and classrooms. Cambridge: Cambridge University Press.

HELLER, M. 1996. Legitimate language in a multilingual school. Linguistics and Education, 8(2): 139-157.

KWENDA, C. 2003. Cultural justice: The pathway to reconciliation and social cohesion. In Chidester, D, P Dexter \& W James (eds), Whatholdustogether: Social cohesion in South Africa. Cape Town: Human Sciences Research Council

LANKSHEAR, C. 1997. Changing literacies. Buckingham: Oxford University Press.

LEIBOWITZ, B. 2004. Becoming academically literate in South Africa: Lessons from student accounts for policymakers and educators. Language and Education, 18(1):3552.

LEIBOWITZ, B. 2001. Students' prior learning and their acquisition of academic literacy at a multilingual South African university. Unpublished PhD dissertation, University of Sheffield.

LIN, A. 1996. Bilingualism or linguistic segregation? Symbolic domination, resistance and code-switching in Hong Kong high schools. Linguistics and Education, 8(1):49-84.

MABOKELA, R. 2000. 'We cannot find qualified blacks': Faculty diversification programmes at South African universities, Comparative Education, 36(1): 95-112.

MCKENNA, S. 2004. The intersection between academic literacies and student identities, South African Journal of Higher Education, 18(3): 269-280.

MCLAREN, P. 1997. Unthinking whiteness; rethinking democracy. In Mclaren, P (ed.), Revolutionary multiculturalism: Pedagogies of dissent for the new millennium. Colorado/Oxford: Westview Press.

MYHILL, J. 2004. Language in Jewish society: Towards a new understanding. Clevedon: Multilingual Matters.

NDAYIPFUKAMIYE, L. 1996. The contradiction of teaching bilingually in post-colonial Burundi: From nyakatsi to maisons en étage. Linguistics and Education, 8(1): 35-47.

NORTON, B. 2000. Identity and language learning; Ethnicity and educational change. London: Pearson Education.

PAVLENKO, A. \& A BLACKLEDGE. 2004. New theoretical approaches to the study of negotiation of identities in multilingual contexts. In Pavlenko, A \& A Blackledge 
(eds), Negotiation of identities in multilingual contexts. Clevedon: Multilingual Matters, 1-33.

NORTON PEIRCE, BN. 1997. Language, identity and the ownership of English, TESOL Quarterly, 31(3): 409-429.

SAYED, Y \& C SOUDIEN. 2003. Integrating South African schools? Some preliminary findings. IDS Bulletin, 34(1): 9-19.

SFARD, A \& A PRUSAK. 2005. Telling identities: In search of an analytic tool for investigating learning as a culturally shaped activity. Educational Researcher, 34(4): $14-22$.

STROOBANTS, V. 2005. Stories about learning in narrative autobiographical research. International Journal of Qualitative Studies in Education, 18(1): 47-61.

WALKER, M. (In Press; 2005) Race is everywhere and race is nowhere: Narratives of black and white South African undergraduates. British Journal of Sociology of Education, 26(1).

WARD, B. 2003. Reflecting on the value and use of the edited topical life history: A research approach. In O' Donoghue, $\mathrm{T} \& \mathrm{~K}$ Punch (eds), Qualitative research in education: Doing and reflecting. London: Routledge Falmer, 26-41.

WENGER, E. 1998. Communities of practice: Learning, meaning and identity. Cambridge: Cambridge University Press.

\section{Biographic Note}

Brenda Leibowitz is Director of the Centre for Teaching and Learning at Stellenbosch University. Her interests are in higher educational development, identity issues and language and learning. At the time of writing the article all team members were working in one of the Academic Support Centres at the University. email: bleibowitz.sun.ac.za 